\title{
Implications of thermal disequilibrium during melt-rock interaction for the evolution of continental lithosphere
}

\author{
MOUSUMI ROY', ALISHA N. CLARK², G. LANG FARMER²
}

Dept of Physics and Astronomy, University of New Mexico, MSC 07-4220, 210 Yale Blvd NE, Albuquerque, NM 87106

Dept. of Geosciences, University of Colorado Boulder, UCB 399, 2200 Colorado Ave. Boulder, CO 80309

It is widely believed that melt-rock interaction plays a key role in the stability and evolution of continental lithospheric mantle. For example, melt-rock interaction has been implicated in the Mesozoic rejuvenation of the North China craton, and in profoundly altering the major and trace element chemistry of several peridotite massifs, including the Lherz massif. Here we use numerical models to explore the consequences of thermal disequilibrium during melt-rock or fluid-rock interaction, focusing on mechanisms for possibly altering the rheology and strength properties of the surrounding rock. The models assume transport in channelized flow in the limit that heat transfer between melt and/or fluid and the surrounding solid dominates over conductive heat fluxes within each phase. Our goal is to quantify the viability of disequilibrium thermal heating as a mechanism for weakening continental lithosphere during melt and/or fluid infiltration during single or multiple, temporallyspaced events.

The spatial scales targeted in these models explore the scales of melt-rock interaction at the lithosphereasthenosphere boundary (LAB), with the goal of understanding the role of melt-infiltration in the evolution of the LAB. The models are motivated by recent geochemical and petrologic evidence from the southwestern North America suggesting that melt-rock interaction is intimately related to changes in the depth of the $\mathrm{LAB}$, even in the absence of lithosphere extension and thinning. Additionally, applications of the model to processes at the edges of thicker portions of the continental lithosphere (e.g., at the edges of cratonic regions) shall be considered. 